\title{
A Review of Complementary and Alternative Medicines for Osteoarthritis
}

\author{
Azidah Abdul Kadir ${ }^{1,2 *}$ \\ ${ }^{1}$ Faculty of Veterinary Medicine, Universiti Putra Malaysia, Malaysia \\ ${ }^{2}$ Department of Family Medicine, School of Medical Sciences, Health Campus, Malaysia
}

Submission: February 02, 2017; Published: August 10, 2018

*Corresponding author: Azidah Abdul Kadir, Department of Family Medicine, School of Medical Sciences, UniversitiSains Malaysia, KubangKerian, 16150, Kelantan, Malaysia; Email: azidahkb@usm.my

\begin{abstract}
Osteoarthritis is a degenerative disease and is the most common arthritis. There is a high prevalence of CAM use among those with osteoarthritis and a large proportion of these sufferers consider these medicines to be safe and effective. Thus, an updated review to look at the current available CAM therapies option and its efficacy and safety is constantly needed. The options of CAM therapies for OA includes exercise, yoga, Tai chi, massage, cupping, manipulative therapy, acupuncture, herbal medicine, leech therapy and Channastriatus (snake head fish extract. The current evidence remains limited and further good quality research are needed.

Keywords: Osteoarthritis;Pain;Complementary;Alternative medicine;Herbal;Traditional;Physical therapy;Acupuncture

Abbreviations: MCHF:Manufactured Chinese Herbal Formulae; QOL: Quality Of Life; RCT: Randomized Controlled Trial; ASU: AvocadoSoyabeanunsaponifiables; OA: Osteoarthritis; CAM: Complementary And Alternative Mediาcine; NSAID: Non-Steroidal Anti-Inflammatory Drugs
\end{abstract}

\section{Introduction}

Osteoarthritis (OA) is the most common joint disease affecting mostly the older people[1]. With increasing prevalence of older people and obesity, it is anticipated that the burden of this disease will be a major issue globally[1]. OA of the knee and hip contributes most of the OA burden and has a major impact in quality of life especially in terms of pain and disability[1].

Currently the management of $\mathrm{OA}$ can be divided into non-pharmacological, pharmacological and surgical[2]. The non-pharmacological management includes education, exercise and weight loss. In the early stage of $\mathrm{OA}$, these management are paramount, but as disease progresses, the need of medication to control symptoms increased[3].The nonpharmacological treatments also is underutilized and most patients resort to pharmacological therapy [4]. Pharmacological therapy is indicated for the patients to control the pain or functional disability due to pain itself [3]. Therefore, current pharmacological therapy mainly target for symptoms relief. There is growing research interest to prevent or slow disease progression since currently there is no pharmacologic agent that can do such[3].

Non-steroidal anti-inflammatory drugs (NSAIDs) and acetaminophen are the two most pharmacological therapy used to control the symptoms due to pain especially in $\mathrm{OA}[5]$.
However, the use of these agent are not without side-effect. Acetaminophen are not as safe as belief [6]. Apart from a wellknown hepatotoxicity, a small study showed that it also can cause upper gastrointestinal (GIT) complications[7]. NSAIDs are effective drugs to control the symptoms of OA but its use is associated with broad spectrum of adverse effects such as GIT, cardiovascular, kidney, liver and skin [8]. Due to these factors, patients with $\mathrm{OA}$ are willing to try complementary and alternative medi $\neg$ cine (CAM) that could provide relief from pain or cure from the illness.

The choice of CAM available for OA are varies such as herbal, nutritional, physical and holistic therapy [9]. The prevalence of CAM used among those with OA range from $40-64.8 \%$ (Morocco 64.8\%[10], USA 47\% [11], Pakistan 45.3\% [12], and Australia $40 \%$ [9]). High CAM used is associated with female gender [913], having more severe disease[10], and had low education [12]. Due to high prevalence of CAM use among patients with $\mathrm{OA}$, it is important to understand why the patients with $\mathrm{OA}$ resort to this CAM therapy. A systematic review study found that most patients with arthritis resorted to CAM therapy due to several factors which includes frustration with conventional therapy and patients. perception that CAM is safe [13]. Due to its popularity, it is important that patients and practitioners have accessible and clear evaluation of the efficacy and safety of 
these treatments. This short review aims to look at the current available CAM therapies option for the patients and its efficacy and safety.

To ease the discussion, CAM use for OA will be divided into;

a) Physical therapy which includes exercise, yoga, Tai chi, massage, cupping, manipulative therapy

b) Acupuncture and moxibustion

c) Herbal medicine

d) Others- leech therapy, Channastriatus (snake head fish extract)

The discussion and consideration of glucosamine and chondroitin was excluded since these have been extensively reviewed in other publications. Glucosamine and Chondroitin are the two which are breaching the gap between alternative and conventional therapy. Originally both are considered a natural therapy for osteoarthritis. Recent studies suggest glucosamine sulphate are not merely symptom modification but also cartilage structural modification[14]. However, the overall the evidence for glucosamine is still conflicting[14-16].

\section{Physical therapy}

Tai Chi, qigong, and yoga are included under CAM mind-body exercises. Findings from the literature suggest that these CAM exercises demonstrate considerable promise in the management of $\mathrm{OA}$ in terms of pain reduction, muscle strength, physical function, stiffness and balance[17-19].

Tai Chi and qigongare both originated from the China and are a form of Traditional Chinese Medicine or exercise. Both are a moderate-intensity mind body exercise with breath control training and features gentle, smooth, graceful, coordinated, and flowing movements of different body parts, emphasizing constant shifting of body weight between two legs with both knees flexed all the time while meditating and breathing deeply[17]. Yoga in another hand origins in ancient Indian philosophy that combines physical postures, breathing techniques, and meditation or relaxation[17].

Cupping is another form of CAM that has been study for relieving the symptoms of knee osteoarthritis (OA). In a randomized controlled exploratory pilot study for 4 weeks, it was found that pulsatile dry cupping significantly reduced the knee OA symptoms compared to the control group[20].

\section{Acupuncture and moxibustion}

The number of patients undergoing acupuncture to treat osteoarthritis has increased over the last few years. [21] Filiform-needle acupuncture, warm-needle moxibustion, and fire-needle moxibustion are three main types of acupuncture and moxibustion[22]. At present, filiform-needle acupuncture, warm- needle moxibustion and fire-needle moxibustion have shown to be effective treatments for knee OA. Two meta- analysis of randomized controlled trials (RCTs) on fire-needle moxibustion and electro-acupuncture in treatment of Knee OA had been conducted and the results showed that both treatments were more effective than control group in symptom management $[22,23]$. However, GRADE analysis indicated that the quality of evidence for all outcomes was relatively low in the meta- analysis for the fire-needle moxibustion[22].

The efficacy of acupuncture as an adjunctive therapy to pharmacological treatment of knee $\mathrm{OA}$ was studied with a 3-armed, single-blind, randomized, sham-controlled trial; it compared acupuncture combined with pharmacological treatment, sham acupuncture including pharmacological treatment, and pharmacological treatmentalone[21]. In the study, patients who underwent acupuncture plus pharmacological treatment had significantly better function and less pain after 8 weeks, compared with patients subjected to sham acupuncture plus pharmacological or pharmacological treatment alone [21]. The side effects of acupuncture were minor (mostly hematomas) which was the known side-effect of this treatment [21]. A recent study showed that high intensity laser radiation which is a relatively new method of application in physical therapy practice is also effective for symptom relieved in knee OA[24].

\section{Herbal medicines}

A big number of herbal medicines had been studied extensively for the treatment of OA. These includes big groups of Chinese traditional medicines, Ayurveda and also western CAM. ]. In a Cochrane systemic review, it was found that majority of the studies were bias and of poor quality. Thus, meta-analyses were restricted to Boswelliaserrata (monoherbal) and avocadosoyabeanunsaponifiables (ASU) (two herb combination) products[25]. In the review, only ASU product Piasclidine ${ }^{\circledR}$ had moderate effect for short term use in knee OA[25]. Among the oral herbal studied in this systematic review were Curcuma domestica, Derris scandens, Harpagophytumprocumbens (Devil's claw), Boswellia serrate, Garcinia kola, Ricinusofficinalis (castor oil), Rosa caninalito(rose hip), Zingiberofficinale(ginger), Salix daphnoides or Salix pupurea $x$ daphnoides (willow), Uncariaguianensis (cat's claw)and Vitellariaparadoxa(shea).

In a recent systematic review done in 2015, manufactured Chinese herbal formulae (MCHF) was assess for effectiveness in treatment of knee OA. A total of 17 kinds of MCHF were identified from the twenty-six included trials. Manufactured Chinese herbal formulae (MCHF), also known as Chinese patent medicine, are typical combination of several Chinese herbals which could enhance the therapeutic effect and reduce the side effect of a single component.

Meta-analyses showed that MCHF significantly relieved the global pain of knee joints, either used alone or combined with routine treatments[26]. However, firm conclusions cannot be made due to the poor methodological quality of included trials[26]. All the trials had no serious adverse and were shown 
to be safe [26]. Among the MCHF studied were Yaotongning capsule and TouguXiaotong capsule.

\section{Others}

The application of medicinal leeches was widely practiced in ancient times. Leech therapy also has been used in the treatment of osteoarthritis[27]. In a randomized controlled trial (RCT), treatment with leech therapy was effective to relieved pain up to day 7 only compared to the control group[27]. Another RCT done among 112 patients for 26 days, It was found that this treatment could alleviate the symptoms of knee OA.

Another CAM that was studied was Channastriatus, a snakehead fish, widely available in South East Asia. The fish is known traditionally for its wound healing properties and relieving pain[28].A randomized, double-blinded, placebo-controlled pilot trial using oral CS extract for 3-month intervention period had been conducted among primary knee osteoarthritis patients. There were significant improvement of pain, symptom scores and quality of life (QOL) domain score $(\mathrm{p}<0.05)$ in those who consumed CS compared to placebo[29].

\section{Conclusion}

The current evidence regarding efficacy of various CAM modalities for osteoarthritis remains highly limited and inconsistent. There is emerging but in most cases low-level of evidence for the efficacy of various CAM in treating osteoarthritis. However, no current evidence does not equate to lack of effectiveness. Rigorous research into the use of complementary medicines in arthritis is evolving and needed to be updated each year.

\section{References}

1. Cross M, Smith E, Hoy D, Nolte S, Ackerman I, Fransen M et al. (2014) The global burden of hip and knee osteoarthritis: estimates from the global burden of disease 2010 study. Ann Rheum Dis 73(7): 1323-1330.

2. Buttgereit F, Burmester GR, Bijlsma JW (2015) Non-surgical management of knee osteoarthritis: where are we now and where do we need to go? RMD Open 1(1): p. e000027.

3. Cheng DS, Visco CJ (2012) Pharmaceutical therapy for osteoarthritis. PM R 4(5 Suppl): S82-8.

4. Austrian JS, Kerns RD, Reid MC (2005) Perceived barriers to trying self-management approaches for chronic pain in older persons. J Am Geriatr Soc 53(5): 856-861

5. Ausiello JC, Stafford RS (2002) Trends in medication use for osteoarthritis treatment. J Rheumatol, 29(5): 999-1005.

6. Scarpignato C, Lanas A, Blandizzi C, Lems WF, Hermann M, et al., (2015) Safe prescribing of non-steroidal anti-inflammatory drugs in patients with osteoarthritis--an expert consensus addressing benefits as well as gastrointestinal and cardiovascular risks. BMC Med 13: p. 55.

7. Gonzalez-Perez A, Rodriguez LA (2006) Upper gastrointestinal complications among users of paracetamol. Basic Clin Pharmacol Toxicol 98(3): 297-303.

8. Wehling M (2014) Non-steroidal anti-inflammatory drug use in chronic pain conditions with special emphasis on the elderly and patients with relevant comorbidities: management and mitigation of risks and adverse effects. European Journal of Clinical Pharmacology 70(10): 1159-1172.

9. Zochling J, March L, Lapsley H, Cross M, Tribe K, Brooks P (2004) Use of complementary medicines for osteoarthritis-a prospective study. Annals of the Rheumatic Diseases 63(5): 549-554.

10. Azzouzi H, Abourazzak FE, Lazrak F, N Kadi, Berraho M, et al. (2016) Complementary and Alternative Medicine in Knee Osteoarthritis: Which Place? SM Journal of Orthopedics 2(4): 1044.

11. Lapane KL (2012) Use of complementary and alternative medicine among patients with radiographic-confirmed knee osteoarthritis. Osteoarthritis Cartilage 20(1): 22-28.

12. Ayaz SB, et al. (2016) The use of complementary health approaches among patients with knee osteoarthritis in Pakistan: A hospital based survey. The Egyptian Rheumatologist 38(2): 111-116.

13. Yang L, Sibbritt D, Adams J (2017) A critical review of complementary and alternative medicine use among people with arthritis: a focus upon prevalence, cost, user profiles, motivation, decision-making, perceived benefits and communication. Rheumatol Int 37(3):337-351.

14. Black C, Clar C, Henderson R, MacEachern C, McNamee P, et al. (2009) The clinical effectiveness of glucosamine and chondroitin supplements in slowing or arresting progression of osteoarthritis of the knee: a systematic review and economic evaluation 13(52):1-148.

15. Wu D, Huang Y, Gu Y, Fan W (2013) Efficacies of different preparations of glucosamine for the treatment of osteoarthritis: a meta-analysis of randomised, double-blind, placebo-controlled trials. Int J Clin Pract 67(6): 585-594.

16. Yang S, Eaton CB, McAlindon TE, Lapane KL (2015) Effects of glucosamine and chondroitin supplementation on knee osteoarthritis: an analysis with marginal structural models. Arthritis Rheumatol 67(3): 714-723.

17. Chyu MC, Vera von Bergen, Jean-Michel Brismée, Yan Zhang, James K. Yeh et al., (2011) Complementary and Alternative Exercises for Management of Osteoarthritis. Arthritis 2011: p. 10.

18. Chang WD, Chen S (2016) The Effects of Tai Chi Chuan on Improving Mind-Body Health for Knee Osteoarthritis Patients: A Systematic Review and Meta-Analysis 2016: p. 1813979.

19. Kan L, Jiaqi Zhang, Yonghong Yang, Pu Wang (2016) The Effects of Yoga on Pain, Mobility, and Quality of Life in Patients with Knee Osteoarthritis: A Systematic Review. Evidence-Based Complementary and Alternative Medicine 2016: p. 10.

20. Teut M, Stefan Kaiser, Miriam Ortiz, Stephanie Roll, Sylvia Binting, et al. (2012) Pulsatile dry cupping in patients with osteoarthritis of the knee - a randomized controlled exploratory trial. BMC Complement Altern Med 12: p. 184

21. Mavrommatis CI, Argyra E, Vadalouka A, Vasilakos DG (2012) Acupuncture as an adjunctive therapy to pharmacological treatment in patients with chronic pain due to osteoarthritis of the knee: a 3-armed, randomized, placebo-controlled trial. Pain 153(8): 1720-1726.

22. Wang Y, Xie X, Zhu X, Chu M, Lu Y, Tian T et al. (2016) Fire-Needle Moxibustion for the Treatment of Knee Osteoarthritis: A Meta-Analysis. Evidence-based Complementary and Alternative Medicine: eCAM 2016: p. 1392627.

23. Shim JW, Jung JY, Kim SS (2016) Effects of Electroacupuncture for Knee Osteoarthritis: A Systematic Review and Meta-Analysis. EvidenceBased Complementary and Alternative Medicine 2016: p. 18.

24. Angelova A, Ilieva EM (2016) Effectiveness of High Intensity Laser Therapy for Reduction of Pain in Knee Osteoarthritis. Pain Research and Management 2016: p. 11. 
25. Cameron M, Chrubasik S (2014) Oral herbal therapies for treating osteoarthritis. Cochrane Database of Systematic Reviews, 22(5).

26. Zhu L, Shaofeng Yang, Shangquan Wang, Hao Gong, Linghui Li, et al. (2015) Effectiveness and Safety of Manufactured Chinese Herbal Formula for Knee Osteoarthritis: Insights from a Systematic Review. Evidencebased Complementary and Alternative Medicine: eCAM 2015: p 328642.

27. Rai PK, Singh OP, Singh AK, Rai NP, Dwivedi AK (2011) Efficacy of leech therapy in the management of osteoarthritis (Sandhivata). Ayu, 32(2): 213-217.

This work is licensed under Creative

Commons Attribution 4.0 License

DOI: 10.19080/JCMAH.2018.06.555691
28. Mat Jais AM (2007) Pharmacognosy and Pharmacology of Haruan (Channa striatus), a medicinal fish with wound healing properties, in Boletin Latinoamericano y del Caribe de Plantas Medicinales y Aromaticas. Derechos de Publication: Santiago, Chile 6(3): 52-60.

29. Kadir AA, Siti Zubaidah Ab Wahab, Maryam Mohd Zulkifli, Norhayati Mohd Noor, Juhara Haron, et al. (2014) The therapeutic effect of the oral Channa striatus extract on primary knee osteoarthritis patients. Agro food Industry Hi Tech 25(3): 44-48.

\section{Your next submission with Juniper Publishers will reach you the below assets}

- Quality Editorial service

- Swift Peer Review

- Reprints availability

- E-prints Service

- Manuscript Podcast for convenient understanding

- Global attainment for your research

- Manuscript accessibility in different formats

( Pdf, E-pub, Full Text, Audio)

- Unceasing customer service

Track the below URL for one-step submission https://juniperpublishers.com/online-submission.php 